UDK: 159.923

Pregledni članak

Primljeno: 9. 7. 2021.

Prihvaćeno za štampu: 6. 11. 2021.

Dr. sc. Dijana Sulejmanović, docent

Univerzitet u Bihaću

Islamski pedagoški fakultet

E-mail:dijana.sulejmanovi@@ipf.unbi.ba

\title{
VELIKIH PET OSOBINA LIČNOSTI VOĐE
}

\section{Sažetak}

O osobinama ličnosti češće se govori kada je potrebno odlučiti o profesionalnoj buduínosti radnika, odrediti da li zaslư̌uje napredovanje ili ne, da li je vrijedan ulaganja na temelju kapaciteta kojima raspolaže i slično. U praksi, kao i u strucnoj literaturi, nalazimo vidlivivo manji broj ispitivanja licnosti lidera, odnosno rukovodilaca ili vođa neke organizacije ili grupe. Iako se naglašavaju kompetencije koje dobar vođa treba imati, obicno su te kompetencije vidliive tek nakon sto neko zaurme poriciju vode. U ovom radu polazimo od problema detekcije osobina ličnosti koje ima dobar voda, bilo da je rijeć o političkom lideru, kapitenu sportskog tima, rukovodiocu radne organizacije ili predstavniku neke neformalne grupe. Prikazom $i$ analizom pregleda radova o osobinama vode, ispituje se koje osobine ličnosti ukazuju da će pojedinac biti dobar vođa, ili da će - unatoč svim drugim kompetencijama, znanjima i vjestinamabiti voden od strane drugih.

Ključne riječi: vođa, vođstvo, psibologija vođstva, ličnost, osobine ličnosti, dimenzije licnosti, Velikih pet, HEXACO

\section{Uvod: pojam vođstva i odrednice ponašanja vođe}

Proučavanjem determinanti ponašanja kojeg nalazimo karakterističnim za osobe na visokopozicioniranim, liderskim funkcijama, uopćeno autoritetima, bilo na temelju kompetentnosti ili moći, nastoje se otkriti faktori koji će olakšati obostranu komunikaciju, doprinijeti međusobnom razumijevanju i povećati uspješnost zajedničkog rada. Poznavanjem nečijih sklonosti ka reagovanju u specifičnim situacijama 
omogućava se proaktivno djelovanje, što dalje vodi ka povećanju djelotvornosti i efikasnosti cijele grupe i onog ko vodi i onih koje vodi.

Prvi radovi socijalnih psihologa o vođstvu vezuju se za Bartlettovu socijalnu psihologiju vođstva (1926) i Nafeov psihološki opis vođstva (1930). Pojam vođstva ne možemo jednostavno definisati. Kako primjećuje Stogdill (1974, prema Yukl, 2008), postoji toliko definicija vođenja kao što postoji osoba koje su pokušale definisati taj pojam. Sinonimi poput termina upravljanje, poslovanje, rukovođenje i sličnih, teško, moglo bi se reći, da pomažu jasnijem određenju. Ipak, od brojnih definicija vođenja, ovdje ćemo se odlučiti za onu Housa i saradnika (1999, str. 184) da je vođenje sposobnost nekog pojedinca da utiče, motivira $i$ osposobi druge da pridonose učinkovitosti $i$ uspjehu organizacije. Osoba od koje se očekuje da izvodi specijaliziranu ulogu vođenja naziva se vođom (Yukl, 2008). Vođa se ne imenuje, ne bira, niti se postavlja - vođom se postaje ako se posjeduju sposobnosti vođe (Tomić i Glavač, 2019).

Svrha pozicije menadžera, lidera ili vođe jeste, ili bi trebala da bude, trajna i neprestana usmjerenost na razvoj svih resursa određene organizacije - osnaživanje postojećih znanja i vještina članova grupe, očuvanje i povećanje materijalnih dobara, praćenje i uključenost $u$ savremena tehnološka dostignuća i maksimalna vidljivost, prepoznatljivost i kvaliteta tržišnog položaja. Razvoj ljudskog potencijala, neupitno najvažnijeg resursa svake organizacije ne može se očekivati u grupi u kojoj vlada nezdrava radna klima, gdje su narušeni međuljudski odnosi i gdje su članovi obespravljeni, diskriminirani i izloženi mobingu, bilo vertikalnom, bilo horizontalnom. Uloga vođe u nekoj organizaciji jeste da svojim primjerom pokazuje drugima kakvim vrijednostima je grupa usmjerena i kakvo djelovanje će biti podsticano, nagrađivano, u svim okolnostima, oblastima i fazama rada, a da bi se postigli optimalni rezultati, dugoročna dobit i zadovoljstvo svih članova. Čak i kada organizacija ne raspolaže potrebnim materijalnim i tehnološkim resursima, vođa će pronaći načine da usmjeri članove organizacije ka djelovanju u korist razvoja i da postojeće slabosti budu nadjačane postojećim snagama.

Razlikujemo tri osnovna stila vođstva - autokratski, demokratski i stil slobodne volje ili laissez-faire (Vander Zanden, 1988). Autokratske vođe samostalno planiraju aktivnosti, samostalno donose odluke, 
pritom ne obavještavajući članove ni o trenutnim, niti o predstojećim aktivnostima, druge uključuju samo kroz kratkoročna zaduženja i, najčešće, istrajavaju u održavanju nesigurne i nepodstičuće radne atmosfere. S druge strane, demokratsko vođenje karakteriše grupni rad - aktivnosti se planiraju uz savjetovanje s ostatkom grupe, članovima se nude mogućnosti izbora (zaduženja saradnika), podstiče se zdrava radna atmosfera, jednakost i ravnopravnost te nagrađivanje isključivo prema zaslugama, a ne prema ličnim preferencijama. Laissez-faire vođa, pak, prije je vođen nego što sam vodi. Ovakvo vođenje prisutno je u grupama gdje ne postoje jasna zaduženja, bitan je cilj, a ne sredstva kojima se do njega dolazi, a za svoj rad članovi niti se pohvaljuju niti se kažnjavaju.

Brojna istraživanja potvrđuju (Banai i Penezić, 2019; Blaker \& Van Vught, 2014; Lautsen \& Peterson, 2016) da ljudi imaju pristranosti prema određenim fenotipima lica prilikom izbora vođe svoje grupe preferiramo vođe s licima koja izgledaju kompetentno, muževno, odnosno ženstveno te ona lica koja su privlačna, odnosno privlačna muška lica četvrtastog oblika, s naglašenom bradom i izraženim obrvama vide se kao muževnija, dominantnija i kao - lica vođe. Prema evolucijskoj teoriji vođstva (Van Vugt \& Ahuja, 2010) u primitivnim društvenim zajednicama vođa je bio onaj koji se dokazao kao najsposobniji za preživljavanje -- u nalaženju skloništa, nabavljanju hrane (Hill, 1982), ali i onaj koji je štitio grupu od neprijatelja i održavao pozitivne, međusobno pomažuće unutargrupne odnose (Cummins, 2009). Vođa grupe u predcivilizacijsko doba bio je onaj koji je mogao grupi obezbijediti miran, siguran i dobar život.

\section{Pregled istraživanja osobina ličnosti vođe}

Kada govorimo o ličnosti, mislimo na relativno trajnu konfiguraciju karakteristika i ponašanja pojedinca, oblikovanog različitim faktorima ili, kako navode Larsen i Buss (2008, str. 4), ličnost je skup psiholoških osobina i mehanizama unutar pojedinca koji su organizirani i relativno trajni $i$ koji utiču na njegovu interakciju s intrapsihičkim, fizičkim $i$ društvenim sredinama $i$ prilagođavanju na njih. Posmatrano kroz dispozicijsku domenu, ličnost se sastoji od osobina, tj. crta ličnosti od kojih je svaka, u nekoj mjeri, prisutna kod svakog pojedinca. Ličnost je ono što omogućava predviđanje šta će osoba uraditi u određenoj 
situaciji (Cattel, 1950: 2-3), određena je postojanjem individualnih razlika u obrascima ponašanja (Međedović, 2020), a osobine ličnosti se odnose na dosljedne obrasce načina na koji se pojedinci ponašaju, osjećaju i misle (Pervin et al., 2008) i koje su stabilne tokom vremena (Fredenburgh, 1971; Larsen i Buss, 2008).

Prema Druckeru (2005) menadžer treba odrediti specifičnu misiju i svrhu djelovanja organizacije, biti od koristi društvenoj zajednici te rad učiniti produktivnim, a uposlenike učinkovitim. Ovo je primjenjivo na vođe bilo kojih organizacija - uspješnost vođe u svakom trenutku je provjerljiva upravo analizom kvaliteta rada njegove grupe, uticajima na društvo te zadovoljstvom i efikasnošću članova grupe koju vodi. Od vođe se očekuje da poznaje potrebe i interese članova grupe, da je otvoren prema novim rješenjima i idejama, da motivira, podstiče i nagrađuje te da raspolaže svim dostupnim resursima uz minimalne gubitke i maksimalne dobitke. Harizmatičnost, stručnost i obrazovanje jesu neophodni za dobro vođstvo, ali su nedovoljni bez osobina ličnosti koje pojedinca čine vođom.

Hassan i saradnici (2016) u pregledu dosadašnjih radova izdvajaju čak 39 stilova vođstva. Kada opisuju vođu čijim su vođenjem zadovoljni ili vođu kakvog trebaju i žele, ljudi obično koriste pridjeve koji se mogu povezati s konkretnim, objektivno vidljivim ponašanjem. Bez obzira da li opisuju demokratski, harizmatični, transformacijski ili neki drugi pozitivni stil vođenja, upotrijebit će termine poput prijatan, posvećen, odgovoran, disciplinovan (Li et al., 2020).

Najveći doprinos u pokušaju mjerenja individualnih razlika dali su modeli ličnosti, od kojih se većina bazira ili na metodi samoizvještaja ili na metodi rejtingovanja (procjene od strane drugih).

Polazeći od modela Velikih pet (Costa \& McCrae, 1985) faktora: Ekstraverzija, Ugodnost, Savjesnost, Emocionalna stabilnost i Intelekt, odnosno petofaktorskog modela ličnosti koji uključuje dimenzije Ekstraverziju, Ugodnost, Savjesnost, Neuroticizam i Otvorenost te novijih istraživanja u kojima je korišten šestofaktorski HEXACO model ličnosti (Ashton et al., 2014) koji je, uz dimenzije koje se preklapaju s dimenzijama petofaktorskog modela ličnosti (Ekstraverzija, Ugodnost, Savjesnost, Emocionalnost i Otvorenost ka iskustvu) dopunjen šestom dimenzijom pod nazivom 
Poštenje/Iskrenost, u ovom radu prikazat će se rezultati dobiveni pri ispitivanju prediktivnosti uspješnog vođenja na temelju vrijednosti na dimenzijama ličnosti. Imajući na umu da navedeni modeli obuhvataju samo "zdrave" osobine ličnosti, fokus rada neće biti na negativnim, nego na pozitivnim osobinama vođe, a u cilju detektovanja koje osobine ličnosti su prediktori dobrog, uspješnog i efikasnog vođstva kada su izražene kod vođe neke grupe.

\section{Ekstraverzija kao osobina ličnosti vođe}

Ekstraverzija, koja obuhvata druželjubivost, traženje iskustava koja omogućavaju socijalne interakcije, toplinu, asertivnost (Sokić et al., 2019) kao osobina ličnosti vođe itekako je poželjna jer je praćena otvorenošću u komunikaciji i interpersonalnim odnosima te socijabilnosti i razvijanjem brojnih socijalnih odnosa (Colquitt, Le-Pine \& Wesson, 2009). Ekstraverti trebaju stalne socijalne kontakte, najefikasniji su kada su okruženi ljudima i ukoliko dođe do deprivacije od socijalnih kontakata, opada i njihova radna efikasnost (Sokić et al., 2019). Ekstraverte odlikuju živahnost, aktivnost i energičnost (Eswaran et al., 2011), a vođe s visokim skorovima na Ekstraverziji češće će tražiti savjete i pomoć drugih kako bi zajednički unaprijedili rad i samu organizaciju (Chiaburu et al., 2011), dok će oni s nižim skorovima na ovoj dimenziji biti inhibirani, plahi, sramežljivi (Goldberg, 1990).

Ekstraverzija je snažan i dosljedan prediktor vođstva, odnosno vođe su, obično, ekstraverti (Blickle et al., 2015; Larsen i Buss, 2008).

\section{Emocionalna stabilnost kao osobina ličnosti vođe}

Prema Goldbergu (1990), emocionalno stabilnim osobama svojstveno je da su mirni, opušteni, stabilni, dok s druge strane osobe koje su nisko na ovoj dimenziji su mrzovoljni, anksiozni i nesigurni te također $\mathrm{i}$ labilni, napeti i povučeni (Sokić et al., 2019).

$\mathrm{Na}$ suprotnom kraju dimenzije Emocionalna stabilnost nalazi se Neuroticizam, koji obuhvata facete anksioznost, strah, osjetljivost, osjećaj krivice (Major et al., 2006), a emocionalno nestabilan vođa često je depresivan, ljut, anksiozan (Eswaran et al., 2011) pokazuje hostilnost, impulsivnost, sputanost i vulnerabilnost (Sokić et al., 2019), nema pozitivan odnos prema poslu i pokazuje nedostatak povjerenja što 
može rezultirati smanjenjem ambicioznosti onih kojima je nadređen. Neracionalnost pri tumačenju postupaka drugih refleksirat će se u lošoj prilagođenosti na stresne situacije, neadekvatnom upravljanju emocijama, nestabilnim i nepredvidljivim reakcijama, napadima bijesa, izostankom opuštenosti u djelovanju i odnosima s drugima, te općim nezadovoljstvom sobom i drugima, ali i povišenim psihosocijalnim rizicima (visok krvni pritisak, srčane tegobe, anksioznost). Emocionalna nestabilnost vođe pogubna je za poslovanje pa, ako je praćena i samohendikepiranjem i visokom ambicioznošću, onemogućava zdravo, realno i objektivno sagledavanje situacije i uspješno rješavanje problema. Vođa - pri čemu mislimo na dobrog vođu, tj. vođu koji ostvaruje rezultate i koji predvodi grupu zadovoljnih, efikasnih i motiviranih članova, ne može imati niske vrijednosti na emocionalnoj stabilnosti jer neće uspješno vladati negativnim emocijama poput ljutnje i anksioznosti. Bit će osjetljiviji na stres, lakše će i burnije reagovati na provokaciju i bit će sklon da iracionalno tumači neprijatne situacije što će voditi daljim burnim, a za grupu pogubnim, relacijma (Bettencourt, Benjamin \& Valentine, 2006; Pease \& Lewis, 2015).

\section{Savjesnost kao osobina ličnosti vođe}

Savjesnost uključuje marljivost, odgovornost, pouzdanost, dobru samokontrolu i organiziranost. Ova osobina, nalazi Penezić sa saradnicima (2013), podrazumijeva pridržavanje pravila, propisa i procedura, ali ne kao neizbježne i nužne obaveze nego kao moralnu orijentiranost uopće. Savjesnost vođe je jedan od najpouzdanijih prediktora efikasnosti rada uposlenika (Hurtz \& Donovan, 2000).

Savjestan vođa (Sokić et al., 2019) je marljiv, odlučan, odgovoran, oprezan i pouzdan, djeluje promišljeno, pridržava se normi i pravila, postavlja i poštuje dugoročne ciljeve, nije usmjeren na kratkoročnu dobit nego na dugoročni uspjeh, motiviše uposlenike da se više trude i ličnim primjerom pokazuje kako bi trebalo da izgleda savjesno poslovanje. On teži ka postignuću, ali promišljeno i organizirano.

Niske vrijednosti na dimenziji Savjesnosti otkrit će vođu koji je neuredan, površan, nepažljiv (Goldberg, 2000), odnosno neorganiziran, neodgovoran i nepraktičan (Daft, 2005), koji insistira na pogrešnim i 
lošim rješenjima kako bi dokazao svoju moć, bez obzira na posljedice koje ovakvo ponašanje može imati za druge članove grupe.

\section{Otvorenost kao osobina ličnosti vođe}

Otvorenost prema (novim) iskustvima ili Intelekt (Eswaran et al., 2011) je dimenzija koja obuhvata sklonost ka traženju nekonvencionalnih rješenja, preispitivanje autoriteta i kritički pristup postojećih, uz spremnost na prihvatanje novih gledišta i tzv. razmišljanje izvan uobičajenih okvira (Rothmann \& Coetzer, 2003). Karakteriše vođu koji je prijemčiv za nova rješenja i nove ideje te stalno traga za promjenama. Vođe s visokim skorom na Otvorenost nisu konvencionalni i slijepo pokorni pravilima, ne plaše se novog i nepoznatog i kroz vlastitu znatiželju i potragu za stimulisanjem mogu i kod članova grupe podsticati razvijanje kreativnosti, korištenje mašte i aktivno, samostalno i slobodno djelovanje.

Otvorenost će se vidjeti u boljoj prilagodljivosti novom i nepoznatom te lakšem suočavanju s promjenama (Chiaburu et al., 2011) i stalnoj spremnosti na usavršavanje te preferiranju različitosti, znatiželji i nezavisnosti u mišljenju (Sokić et al., 2019).

Visoka Otvorenost povezana je s transformacionim i etičkim vođstvom (Brown et al., 2005; Judge \& Bono, 2000) dok nisku nalazimo kod autokratskih vođa.

\section{Ugodnost / Saradljivost kao osobina ličnosti vođe}

Ugodnost kao osobina ličnosti podrazumijeva pristojnost, ljubaznost, kooperativnost, povjerljivost, tolerantnost, ali i privrženost, brižnost prema drugima i altruističnost te blagost, pomirljivost, iskrenost (Daft, 2005; Prewett et al., 2009; Sokić et al., 2019).Vođa s visokim vrijednostima na dimenziji Ugodnost ne upušta se u socijalne sukobe i preferira kompromis, popuštanje i povlačenje, saosjećajan je, iskren i pun razumijevanja prema drugima (Goldberg, 2000). Ova osobina pozitivno je povezana $\mathrm{s}$ pomažućim, a negativno $\mathrm{s}$ devijantnim $\mathrm{i}$ neproduktivnim ponašanjem (Salgado, 2002).

Niska Ugodnost kod vođe ogleda se u grubosti, okrutnosti i nesaosjećajnosti, a za posljedicu može imati visoko socijalno 
besposličarenje, tj. zabušavanje u grupi (Comer, 1995). Vođa s niskim vrijednostima, pak, jeste vođa koji je sebičan i neljubazan (Daft, 2005), ne pokazuje brigu za druge, razdražljiv je i neprijateljski raspoložen, nepovjerljiv je prema saradnicima, ne poštuje ih i to otvoreno pokazuje omalovažavanjem i isključivanjem iz aktivnosti koje bi članu grupe donijele materijalnu korist ili drugi oblik nagrade na koju ima pravo. Cinizam i agresivna kompetetivnost stalno su prisutni u komunikaciji sa saradnicima. Ovakve vođe su osvetoljubivi i pokazuju bezobzirnost prema drugima (Bettencourt, Benjamin \& Valentine, 2006).

Saradljivost je posebno, nalaze Bono i Judge (2004), povezana s harizmatičnim vođstvom.

U HEXACO modelu ličnosti ova dimenzija označena je kao Saradljivost i obuhvata facete tendencija opraštanja, nježnost, fleksibilnost, strpljivost i otkriva mirne, nježne, strpljive i prijatne osobe (Ashton et al., 2014). Viši skor na ovoj dimenziji možemo očekivati kod vođe koji norme za vlastito ispravno ponašanje usvaja od različitih izvora - partnera, prijatelja, za razliku od onih koji prate samo vlastito mišljenje. Ekstremne vrijednosti na kontinuumu ove dimenzije su saosjećajnost i saradljivost $u$ pozitivnom, a sebičnost i kompetitivnost u negativnom smjeru.

\section{Poštenje kao osobina ličnosti vođe}

Leksički model Ashtona i Leeja (2001), kako je već ranije navedeno, proširen je u odnosu na petofaktorski model ličnosti faktorom Poštenje koji uključuje facete iskrenost, pravednosti, skromnosti te izbjegavanja pohlepe.

Visok skor na Poštenju značit će vođu koji nije sklon manipulisati drugima, dok niski skorovi ukazuju na sklonost da se naklonost drugih stiče laskanjem. Slatkorječiv vođa, drugim riječima, spreman je ličnu korist ostvariti varanjem, podmetanjem ili krađom (Sokić et al., 2019). Pritom, sebe vidi sposobnijim i kompetentnijim u odnosu na druge i to stalno i neskromno ističe, a sklon je da iskorištava i sabotira druge $u$ svom radnom okruženju (Zettler \& Hilbig, 2010). 


\section{Umjesto zaključka}

It's not who I am underneath, but what I do that defines me.

(Nolan, 2005, prema Li et al., 2020)

Vođa je, obično, onaj koji se nalazi na liderskoj poziciji, tj. na čelu određene organizacije (Hogan \& Kaiser, 2005), premda bi ispravnije bilo vođu odrediti kao onoga koji gradi i održava grupu da postiže bolje rezultate $\mathrm{u}$ odnosu na konkurenciju. Iz ove perspektive posmatrano, vođa bi morao imati intrapersonalne kompetencije (da umije kontrolisati emocije i ponašanje, da ima autoritet i integritet, da poštuje moralne i etičke vrijednosti), interpersonalne (da ima dobre oralne vještine, da umije slušati, da gradi međusobno uvažavajuće odnose), poslovne (da ima jasnu i efikasnu poslovnu strategiju, da donosi kvalitetne odluke, da povećava efikasnost i kvalitet rada) te liderske kompetencije (da podržava, razvija, motiviše, gradi, vodi).

Brojni različiti stilovi vođstva ne mogu nam dati potpuno tačan odgovor koji stil je najbolji. U političkom vođstvu, naprimjer, poželjnije je da vođa ima dominatnije izraženu saradljivost, savjesnost i otvorenost, kao i emocionalnu stabilnost (Winter, 2003), iako navedene osobine ukazuju na poželjnog vođu u svim sferama i oblicima vođenja grupe. U nekim grupama određeni stil vođstva će biti efikasniji, premda pritom vođa sam ne mora vjerovati u njegovu efikasnost, ali primjenjuje ono što se od njega očekuje ili podrazumijeva (naprimjer, autokratski stil u vojsci). Osobine ličnosti, pak, ne možemo „podešavati“ u skladu sa socijalnom poželjnosti djelovanja. Pojedinac općenito, a podrazmijeva se i vođa, ako je visoko, naprimjer, na Poštenju, on će težiti da djeluje iskreno, pravedno, skromno i da izbjegava pohlepu u svim situacijama. Dosljednost u ponašanju, nadalje, vodit će porastu povjerenja u vođu od strane članova grupe, jačanju međusobnih odnosa, posvećenošću općoj dobrobiti i napretku, razvoju grupe.

Vođa čija se reakcija ne može predvidjeti u običnim, svakodnevnim aktivnostima, vođa koji je nedosljedan, koji ne postavlja jasne ciljeve i ne usmjerava grupu u pravcu ostvarivanja istih, nije vođa nego je vođen. Ovakvog vođu svaka socijalna struja može preusmjeriti, on nije čvrst u stavovima, niti odlukama i pravo vođstvo u ovakvim grupama pripada onome koji vodi vođu. Vođeni, pritom, nisu bitni. 
Zašto je važno biti dobar vođa? Za razliku od grupnog uspjeha i zajedničkih benefita za sve članove grupe koju predvodi dobar vođa, u onim grupama gdje zvanični vođa ne umije voditi i gdje je i on sam vođen $\mathrm{i}$ prepušten različitim spoljašnjim djelovanjima, neprimjereno ponašanje vođe i neadekvatno pogrešno vođenje, bit će prepoznati od strane grupe i, ukoliko ne mogu biti promijenjeni ili eliminisani, rezultirat će, sasvim vjerovatno, napuštanjem grupe od strane najvještijih i najsposobnijih članova koji tako postaju direktna konkurencija i prijetnja jer poznaju slabosti kako same grupe, tako i vođe grupe. S druge strane, uz loše vođenje u grupi ostaju oni članovi čija znanja i vještine im ne dopuštaju rizik i koji, s takvim nedostatnim sposobnostima "nose" grupu.

U radu se nismo bavili sljedbenicima, odnosno osobinama onih koji prate vođu i održavaju ga na čelu grupe. Fokus rada bio je, na temelju vidljivih obrazaca ponašanja, zaključiti koje osobine ličnosti odlikuju uspješnog, dobrog vođu, a izostanak kojih će, pak, ukazivati na lošeg vođu, odnosno loše vođstvo.

Pored ranije navedenih gubitaka po cijelu grupu u slučajevima kada istom rukovodi vođa koji je nepošten, introvert, nesavjestan..., najpogubnije djelovanje na grupu, njenu efikasnost, unutargrupne relacije, zadovoljstvo i psihološku dobrobit članova grupe, nalazimo kada su kod vođe grupe prisutne ove negativne crte ličnosti, a niti on, niti članovi grupe čiji je vođa ne prepoznaju loše vođenje. Loši sportski rezultati, novčani gubici, poraz na izborima i gubitak vlasti te trajno narušeni međuljudski odnosi samo su neki od mogućih i sasvim izvjesnih ishoda lošeg vođstva. Bez obzira na stil vođstva, resurse, mogućnosti i izazove, "pogrešan" sklop ličnosti vođe, odnosno vođa koji nema osobine vođe, a pritom ima primjetne osobine koje ne karakterišu dobrog vođu, ostavit će trajne posljedice po svaku grupu. Umjesto izreke "Ako želite uništiti neko društvo, uništite mu školstvo", još tačnijom se čini "Ako želite uništiti neko društvo, dajte mu lošeg vođu".

\section{Literatura}

Ashton, M. C., Lee, K., and de Vries, R. E. (2014) The HEXACO HonestyHumility, agreeableness, and emotionality factors: a review of research and theory. Pers. Soc. Psychol. Rev. 18, 139-152. 
Ashton, M. C. \& Lee, K. (2001) A theoretical basis for the major dimensions of personality. European Journal of Personality, 15, 327-353.

Banai, B. i Penezić, Z. (2019) Kako izgleda vođa? Evolucijski pogled na pristranost prema obilježjima lica vođa. Psihologijske teme, 28 (3), 549566.

Bartlett, F. C. (1926) The social psychology of leadership. Journal of the National Institute of Industrial Psychology, 3, 188-193.

Bettencourt, B. A., Talley, A., Benjamin, A. J. i Valentine, J. (2006) Personality and aggressive behavior under provoking and neutral conditions: A meta-analytic review. Psychological Bulletin, Vol. 132 No.5, str. 751-777.

Blaker, N. M. \& Van Vugt, M. (2014) The status-size hypothesis: How cues o physical size and social status influence each other. In: J. T. Cheng, J. L. Tracy \& C. Anderson (Eds.), The psychology of social status (pp. 119137), New York, NY: Springer.

Blickle, G., Meurs, J. A., Wihler, A., ewen, C., Merk1, R. \& Missfeld, T. (2015) Extraversion and Job Performance: How Context Relevance and Bandwith Specificity Create A Non-Linear, positive and Asymptotic Relationship. Journal of Vocational Behavior, 87, 80-88.

Brown, M. E., Trevino, L. K. \& Harrison, D. A. (2005) Ethical leadership: A social learning perspective for construct development and testing. Organizational Behavior and Human Decision Processes, 97, 117-134.

Cattell, R. B. (1950) Personality: A systematic theoretical and factual study. New York: McGraw-Hill.

Chiaburu, D. S., Oh, I. S., Berry, C. M., Li, N., i Gardner, R. G. (2011) The fivefactor model of personality traits and organizational citizenship behaviors: a metaanalysis. Journal of Applied Psychology, Vol. 96 No. 6, str. 1140-1166.

Colquitt, J., Le-Pine, J. \& Wesson, M. (2009) Organizational behavior, improving performance and commitment in the workplace. New York: McGraw-Hill, Irwin.

Comer, D. R. (1995) A model of social loafing in real work groups. Human Relations, 48, 647-667.

Costa, P. T., Jr. \& McCrae, R. R. (1985) The NEO personality inventory manual. Psychological Assessment Resources: Odessa, FL. 
Cummins, J. (2009) Issue voting and crime in gubernatorial elections. Social Science Quarterly, 90, 632-651.

Daft, R. L. (2005) The Leadership Experience, 3rd Edition. US: Thomosn south-western.

Drucker, P. (2005) Najvažnije o menadžmentu. Zagreb: M. E. P. Consult.

Eswaran, S., Islam, A., Yusuf, D. H. M. (2011) A Study of the Relationship between the Big Five Personality Dimensions and Job Involvement in a Foreign Based Financial Institution in Penang. International Business Research, 4(4), 164-175.

Fredenburgh, F. (1971) The Psychology of Personality and Adjustment. Philipines: Cummings Publishing Company.

Goldberg, L. R. (1990) An alternative "description of personality": the bigfive factor structure. Journal of Personality and Social Psychology, 59, $1216-1229$.

Hassan, H., Asad, S. \& Hoshino, Y. (2016) Determinants of Leadership Style in Big Five Personality Dimensions. Universal Journal of Management, 4 (4), 161-179.

Hill, K. (1982) Hunting and human evolution. Journal of Human Evolution, 11 (6), 521-544.

Hogan, R. \& Kaiser, R. B. (2005) What We Know About Leadership. Review of General Psychology, 9(2), 169-180.

House, R. J., Hanges, P. J., Ruiz-Quintanilla, S. A., Dorfman, P. W., Falkus, S. A. \& Ashkanasy, N. M. (1999) Cultural influences on leadership and organizations: Project Globe. Advances in Global Leadership, 1, 171-233.

Hurtz, G. M. \& Donovan, J. J. (2000) Personality and job performance: The Big Five revisited. Journal of Applied Psychology, 85 (6), 869-879.

Judge, T. A. \& Bono, J. E. (2000) Five-Factor Model of Personality and Transformational Leadership. Journal of Applied Psychology, 85(5), 751765.

Larsen, R. J. i Buss, D. M. (2008) Psihologija ličnosti. Jastrebarsko: Naklada Slap.

Lautsen, L. \& Petersen, M. B. (2016) Winning faces vary by ideology: How nonverbal source cues influence election and communication success in politics. Political Communication, 33 (2), 188-211. 
Li, W.-D., Li, S., Feng, J. J. et al. (2020) Can becoming a leader change your personality? An investigation with two longitudinal studies from a rolebased perpsective. Journal of Applied Psychology, 106 (6), 882-901.

Major, D. A., Turner, J. E. \& Fletcher, T. D. (2006) Linking proactive personality and the big five to motivation to learn and development activity. Journal of Applied Psychology, 87, 530-541.

Međedović, J. (2020) Big Five traits as (mal)adaptive behavioral responses to harsh and unpredictable environment: Further evidence for the statedependent evolution of personality. Psihološka istraživanja, 23 (1), $23-41$.

Nafe, R. W. (1930) A psychological description of leadership. Journal of Social Psychology, 1, 248-266.

Pease, C. R. \& Lewis, G. J. (2015) Personality links to anger: Evidence for trait interaction and differentiation across expression style. Personality and Individual Differences, Vol. 74, str. 159-164.

Penezić, Z., Rak, I. i Slišković, A. (2013) Odgovorno oganizacijsko ponašanje: provjera konstrukta na hrvatskom uzorku. Društvena istraživanja, 22 (1), 121-141.

Pervin, L. A., Cervone, D. i John, O. P. (2008) Psihologija ličnosti: teorije i istraživanja. Zagreb: Školska knjiga.

Prewett, M. S., Walvoord, A. A. G., Stilson, F. R. B., Rossi, M. E., \& Brannick, M. T. (2009) The team personality-team performance relationship revisited: The impact of criterion choice, pattern of workflow, and method of aggregation. Human Performance, 22(4), 273-296.

Rothmann, S. \& Coetzer, E. (2003) The Big Five personality dimensions and job performance. Journal of Industrial Psychology, 29(1), 68-74.

Salgado, J. (2002) The Big Five personality dimensions and counterproductive behaviours. International Journal of Selection and assessment, 10, 117-125.

Sokić, K., Gutić Martinčić, S. i Bakić, M. (2019) Uloga ličnosti u organizacijskom ponašanju. FIP - Financije i pravo, 7(2), 23-50.

Tomić, Z. i Glavač, K. (2019) Političko vodstvo. South Eastern European Journal of Communication, 1 (1), 9-20.

Vander Zanden, J W. (1988) The Social Experience. New York: Random House. 
Van Vugt, M., Ahuja, A. (2010) Selected: Why some people lead and others follow, and why it matters. London, UK: Profile.

Winter, D. (2003) Personality and Political Behavior. In: D. O. Sears, L. Huddy \& R. Jervis (Eds.), Oxford Handbook of Political Psychology, pp. 110-145. Oxford: University Press.

Yukl, G. (2008) Rukovođenje u organizacijama. Jastrebarsko: Naklada Slap.

Zettler, I. \& Hilbig, B. E. (2010) Attitudes of the selfless: Explaining political orientation with altruism. Personality and Individual Dfferences, 48 (3), $338-342$. 
Dijana Sulejmanović, PhD

University of Bihac

Islamic Pedagogical Faculty

E-mail: dijana.sulejmanovic@ipf.unbi.ba

\section{BIG FIVE PERSONALITY TRAITS OF A LEADER}

\section{ABSTRACT}

When it is necessary to decide on the professional future of a worker, or to determine does he deserve promotion or does he worth investing based on the capacities he has, the importance of the personality traits is more often highlighted. In practice, as well as in the scientific literature, we find a visibly smaller number of articles about personality of a leader. Although the competencies that a good leader should have are emphasized, usually these competencies are visible only after someone takes the position of leader. In this paper, we start from the problem of detecting personality traits that a good leader has, whether it is a political leader, captain of a sports team, head of a work organization or a representative of an informal group. By reviewing and analyzing a review of papers on leader traits, we examine which personality traits indicate that an individual will be a good leader, or - despite all other competencies, knowledge and skills - will he be led by others.

Key words: leader, leadership, leadership psychology, personality, personality traits, personality dimensions, Big Five, HEXACO 
الأستاذة المحاضرة ديانا سوليمانوفيتش

جامعة بيهاتش

كلية التربية الإسلامية

dijana.sulejmanovic@ipf.unbi.ba

\section{الصفات الخمسة العظيمة للشخصية القيادية}

\section{الخلاصة}

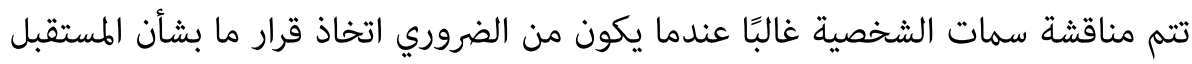

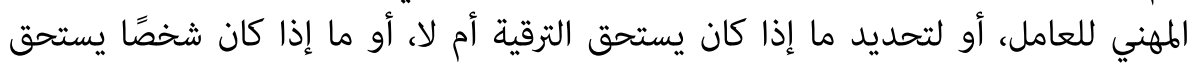

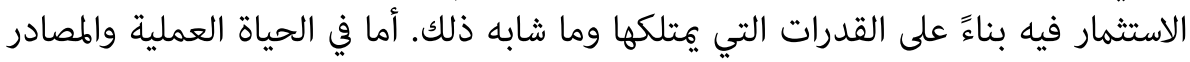

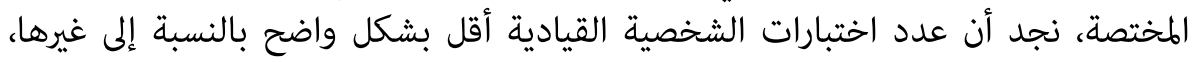
وذلك يتضمن القائد أو رئيس منظمة أو أو مجموعة ما.

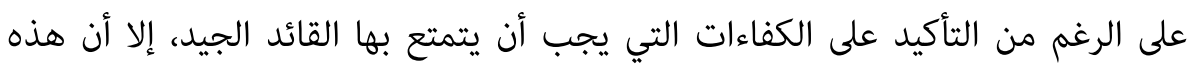

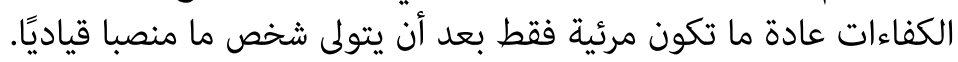

نقطة البدء في هذا البحث هي مشكلة اكتشاف السمات الشخصية للقائد الجيد، سواء كان

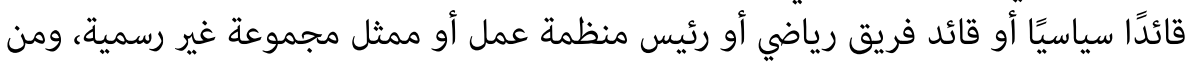

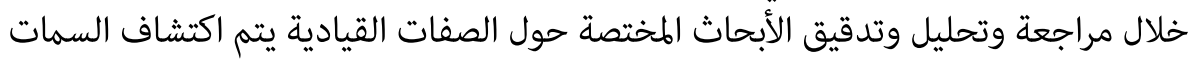

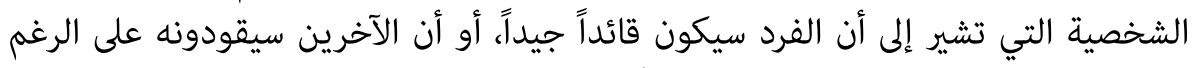
من جميع الكفاءات والكعارف والكهارات الأخرى التي يمتلكها. الكلمات المفتاحية: قائد، قيادة، علم نفس القيادة، شخصية، السمات الشخصية، أبعاد

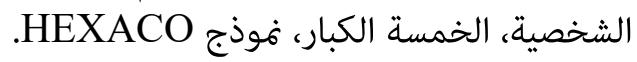

